\title{
Evaluation of Severity of Malaria Infection and Effect of Anti-malaria Drugs on Gender Differences Using Blood Cell Lines Parameters
}

\author{
ESAN AYODELE. $\mathrm{J}^{1, *}$, OMISAKIN C. $\mathrm{T}^{1}$, TITILAYO OYEDELE. $\mathrm{E}^{2}$, FASAKIN KOLAWOLE ${ }^{1}$ \\ ${ }^{1}$ Haematology Department, Federal Medical Centre, Ido-Ekiti, Ekiti State Nigeria \\ ${ }^{2}$ ACHIEVERS UNIVERSITY, OWO, ONDO STATE, NIGERIA \\ *Corresponding author: ayodelejacob4u@gmail.com
}

Received April 04, 2014; Revised May 21, 2014; Accepted October 07, 2014

\begin{abstract}
Malaria is a serious public health problem in most countries of the tropics. In Nigeria about 96 million people are exposed to malaria, and out of these 64 million people get infected and almost 300,000 deaths are being reported annually in the general population. The aim of the study therefore is to determine severity and prevalence of malaria infection and effect of anti-malaria drugs on gender differences causing changes in the blood cell lines. 202 confirmed malaria infected patients were recruited for the study between the ages of $15-64$ years of both sexes at the general outpatient clinic of the Federal Medical Centre, Ido-Ekiti, Ekiti State, Nigeria. 4ml of blood sample was collected twice from the same patient before and after taking anti-malaria drug into di-potassium ethylenediaminetetracetic acid vaccutainer bottles for blood cell lines analysis. Malaria parasite detection, malaria parasite count and malaria parasite species identification were also carried out. All the subjects were infected with Plasmodium falciparum specie; out of the 202 malaria infected patients 129(63.9\%) were males and 73(36.1\%) were females. Mean \pm SD of MPC, MPV, WBC, absolute neutrophil in male was significantly $(\mathrm{P}<0.05)$ higher compared to female in pre and post anti- malaria drug treatment. Plasmodium falciparum is the most prevalent malaria specie in the study area. Severity and prevalence of malaria infection is more in male compared to female this might be as a result of different exposure to malaria vector and immunity to parasitic infection among the gender.
\end{abstract}

Keywords: malaria parasite, gender, blood cell lines

Cite This Article: esAn AYODELE. J, OMISAKIN C. T, TITILAYO OYEDELE. E, and FASAKIN KOLAWOLE, "Evaluation of Severity of Malaria Infection and Effect of Anti-malaria Drugs on Gender Differences Using Blood Cell Lines Parameters." American Journal of Medical Sciences and Medicine, vol. 2, no. 5 (2014): 89-95. doi: 10.12691/ajmsm-2-5-2.

\section{Introduction}

Malaria is a serious public health problem in most countries of the tropics. It is a major cause of mortality and morbidity, between 300 and 500 million people suffer acute cases of malaria infection in 100 developing countries each year, and the majority of the victims were children [1]. More than $90 \%$ of these deaths occur in subSaharan Africa, most of them are due to plasmodium falciparum [2]. Severe plasmodium falciparum malaria has been associated with an increase in oxidative stress, in relation with disease severity [3,4,5]. In Nigeria about 96 million people are exposed to malaria, and out of these 64 million people get infected and almost 300,000 deaths are being reported annually in the general population, of which over 100,000 deaths are of children [6]. However, the available data indicates that malaria is the most common cause of outpatient visits. It ranks among the five most common causes of death for all ages and represents 8-12\% of childhood deaths under the age of five years [7]. In Nigeria and West African sub-region, the major vectors are Anopheles gambiae sensu stricto (ss), A. arabiensis, A. funestus and $A$. melas. In the savanna regions, the most dominant species is $A$. arabiensis, while A. gambiae is highly dense in the forest areas. Anopheles funestus has an uneven distribution while $A$. melas, a salt water breeding form, is essentially a coastal species. These mosquitoes thrive in warm humid environments including rice paddies. Malaria is caused by protozoan parasites belonging to the genus plasmodium which infects and destroys red blood cells. Four species of plasmodia (Plasmodium falciparum, Plasmodium malariae, Plasmodium ovale and Plasmodium vivax) cause malaria in humans of which Plasmodium falciparum is the most dangerous form of malaria and life threatening in an unprotected, non-immune population causing high morbidity and mortality. Malaria parasite completes their life cycle in two hosts, the sexual cycle (which produces merozoites and schizogony) occurs inside the red blood cells of the vertebrate host (intermediate hosts) while the asexual cycle (which produces sporozoites and sporogony) occurs in the invertebrate hosts (definitive hosts) a mosquito [8]. During a sexual development, the parasite takes at first the form of a ring and later of trophozoites in which malaria 
pigment appears. Later still, the chromatin divides, becomes surrounded by pieces of the cytoplasm and the mature parasite at this stage is known as schizont; having undergone erythrocytic schizogony, some merozoites instead of developing into trophozoites and schizonts, give rise to gametocytes which develop in the red blood cells (RBCs) of the capillaries of internal organs (gametogony). Peripheral blood reveals only the mature gametocytes. Gametogony is completed in four days time and a person carrying these gametocytes (carrier) is infective to the vector mosquito species. Artemisinin, is the key ingredient obtained from Artemisia annua, it has two synthetic derivatives, artemether and sodium artesunate, it is a powerful oxidant. Artemisinin and its derivatives are a group of drugs that possess the most rapid action of all current drugs against malaria parasite [9]. Artemisinins, especially artesunate and artemether, result in more rapid parasite clearance (being active on the immature parasite forms) and are safer and simpler to administer. Artemisinins reduce parasite numbers by a factor of approximately 10,000 in each asexual cycle, which is more than other current anti-malaria drugs (which reduce parasite numbers 100 - to 1000 - fold per cycle) [10]. Artemisinins are generally well tolerated at the doses used to treat malaria. The side effects from the artemisinin class of medications are similar to the symptoms of malaria: nausea, vomiting, anorexia, and dizziness. Mild blood abnormalities (neutropenia) have also been noted. Adverse effects in patients with acute $P$. falciparum malaria treated with artemisinin derivatives tend to be higher [11]. All artemisinins used today are pro-drugs of the biologically active metabolite dihydroartemisinin, which is active during the stage when the parasite is located inside red blood cells [12]. Despite prevention and control efforts, malaria still remains a leading cause of morbidity and mortality worldwide. The true burden of malaria is difficult to estimate as many people are treated at home and no proper post-mortem diagnosis is made in the case of death. As a result, many malaria cases go unreported. A gender approach contributes to both understanding and combating malaria. Gender norms and values that influence the division of labour, leisure patterns, and sleeping arrangements may lead to different patterns of exposure to mosquitoes for men and women. In some societies, men tend to sleep outdoors and this may increase their risk of exposure to mosquitoes [13]. There are also gender dimensions in the accessing of treatment and care for malaria, and in the use of preventative measures such as mosquito nets. A thorough understanding of the gender-related dynamics of treatment-seeking behaviour, as well as of decisionmaking, resource allocation and financial authority within households is a key to ensuring effective malaria control programmes. Therefore, gender and malaria issues are increasingly being incorporated into malaria control strategies in order to improve their coverage and effectiveness in different contexts. In some societies, men have a greater occupational risk of contracting malaria than women if they work in mines fields or forests at peak biting times, or migrate to areas of high endemicity for work [14]. Women who get up before dawn to perform household chores may also be exposed to mosquitoes and consequently to malaria infection [15]. In other societies, the activities of men and women during peak biting times may result in equal risks of infection. For example, a study in Myanmar on activities that enhance human-vector contact revealed that gender-specific patterns of both leisure and work activities during peak biting periods by men and women placed them at equal risk of contracting malaria through exposure to mosquitoes [16]. The division of labour as a result of gender roles may play a significant part in determining exposure to mosquitoes. However, very few studies have been conducted to specifically look at this. Understanding how gendered patterns of behaviour influence exposure to mosquitoes can therefore assist in developing more-effective recommendations for preventing malaria infection. Anti-malaria drug may be associated with a decline in the total white cell and neutrophil counts; neutropenia is related to increased splenic sequestration. A variety of haematological and blood cells alterations in malaria have been reported by various studies, as blood counts are now readily available with the use of automated analyzers, even at the primary health care centres. These include progressively decreasing haemoglobin, thrombocytopenia, leucocytosis, leucopaenia, reticulocytosis and disseminated intravascular coagulation $[17,18,19]$. Haematological abnormalities that have been reported in malaria infection include anaemia, thrombocytopenia, splenomegaly, and mild-to-moderate atypical lymphocytosis and rarely disseminated intravascular coagulation (DIC). There have also been reports of leucopenia and leucocytosis [20]. Other haematological reactions to malaria infection that have been reported include neutropenia, eosinophilia, neutrophilia and monocytosis [21,22]. However, eosinophilia has been reported to occur after initiation of antimalaria treatment [20]. Phagocytosis of malaria pigment by monocytes/ macrophages, and less frequently by neutrophils, has been observed in peripheral blood cells and bone marrow of patients with malaria [20,22,23]. Malaria infection decrease lymphocyte count, this was observed in the untreated group, is striking as lymphocytes, particularly $\mathrm{T}$ cells, play a major role in immunity to $P$. falciparum malaria by releasing proinflammatory cytokines such as TNF, interferon and other cytokines, and activating other inflammatory cells, phagocytosis of parasite-infected red blood cells release cytokines. However, excessive secretion of the proinflammatory cytokines contributes to disease severity [24]. White blood cells (WBC) play a vital role in the body's immune defence against disease. The number of WBC may be reduced or increased depending on a disease condition or a reaction occurring in the body, such reactions could be normal or abnormal. WBCs are indirectly and relatively used in estimating Plasmodium parasitaemia by counting, on microscopic examination of Giemsa-stained blood smears, the number of parasites against a predetermined number of WBC [25]. Leukocytosis is typically reported in a fraction of cases and may be associated with concurrent infections and/or poor prognosis. Monocytes have also been reported to act against the malaria parasite through several mechanisms; the higher WBC, lymphocyte and granulocyte counts during the progress of malaria could be associated with severe or acute malaria [26]. The aim of the study therefore is to determine severity and prevalence of malaria infection and effect of anti-malaria drugs on gender differences causing changes in the blood cell lines 
of adult patients with acute uncomplicated malaria attending our hospital facility.

\section{Materials and Methods}

\subsection{Subjects Selection}

Two hundred and two confirmed malaria infected patients were recruited for the study between the ages of $15-64$ years of both sexes at the general outpatient clinic of the Federal Medical Centre, Ido-Ekiti, Ekiti State, Nigeria. One hundred and two apparently healthy malaria negative subjects were drowning from hospital staff at Federal Medical Centre, Ido-Ekiti which serves as study control group and comprising both sexes between the ages 15 - 64years within March 2012 and November 2013. The study was conducted with an informed consent of the patients. Ethical approval was obtained from ethical committee of Federal Medical Centre, Ido-Ekiti, Ekiti State.

\subsection{Sample Collection}

About $4 \mathrm{ml}$ of blood sample was collected from each subject on the first day of visiting hospital as baseline sample grouped as pre anti-malaria drug treatment sample, after the patient has been clinically diagnosis for malaria infection and confirmed using malaria rapid kit, another $4 \mathrm{ml}$ of blood sample was collected on the second or third day from the same patient after taking anti-malaria drugs grouped as post anti-malaria drug treatment sample. Blood sample collected was dispensed into di-potassium ethylenediaminetetracetic acid ( $\mathrm{K}_{2}$ EDTA) vaccutainer bottles used for blood cells parameters analysis using haematology analyzer (sysmex model KX-21N), white blood cells differential was counted manually using thin blood film stained with Leishman staining technique for proper identification of white blood cells. Malaria parasites were screen for using commercially prepared malaria rapid test kit; also thick and thin blood film was made for microscopic gold standard diagnosis of malaria parasite infection; for malaria parasite detection, malaria parasite count and malaria parasite species identification. Questionnaire was used to obtain the demographic characteristics and other relevant information for the study.

\subsection{Methodology}

\subsubsection{Diagnosis of Malaria Parasite Using A Rapid Diagnostic Kit Test}

Malaria plasmodium falciparum was screened for using commercially prepared malaria rapid test kit. The test device is a rapid chromatographic immunoassay for the qualitative detection of circulation of plasmodium falciparum in whole blood.

\subsubsection{Principle}

The malaria plasmodium falciparum rapid test device (whole blood) is a qualitative, membrane based immunoassay for the detection of plasmodium falciparum antigen in whole blood. The membrane is pre-coated with anti-HRPII antibody. During testing, the whole blood specimen reacts with the dye conjugate, which has been pre-coated in the test strip. The mixture then migrates upward on the membrane chromatographically by capillary action and reacts with anti-HRP-II antibody on the membrane on the test line. If the specimen contains HRP-II, a coloured line will appear in the test region. The absence of the coloured line in the test region indicates that the specimen does not contain HRP-II. To serve as a procedure control, a coloured line will always appear in the control region indicating that proper volume of specimen has been added and membrane wicking has coloured.

\subsubsection{Procedure}

The procedure was as described by the manufacturer of the kit (Acon Laboratories, Inc.). 20ul of whole blood was pipette into clean labelled test tube, 120ul of buffer solution was added and waited for 1 minutes, contents in the test tube was mixed, 140ul of mixed blood sample and buffer solution was pipette into specimen well on test device and wait for colour line(s) to appear. The result was read at 15 minutes.

Interpretation of results: for positive result, two distinct coloured lines were appeared: one line was in control region and another line was in test region. For negative result: only one coloured line was appeared in the control region, result was invalid if control line fails to appear

\subsection{Microscopic Diagnosis of Malaria Parasite Using Thick And Thin Stained Blood Film}

\subsubsection{Thick and Thin Stained Blood Film}

Thick blood film was made from EDTA blood sample and stained using Giemsa's staining technique for malaria parasite detection and malaria parasite count. However, thin blood film was also made from well mixed anticoagulated EDTA blood sample and stained with Leishman staining technique for plasmodium species identification. Changes in parasitized red cells help to identity plasmodium species and to detect mixed infection of malaria parasite. The number of asexual $P$. falciparium and other species per 200 leukocytes were counted and if ten or more parasites were identified, then the number was recorded, a blood sample was regarded as negative if the examination of thick films failed to show the presence of asexual parasites. The parasite count in relation to the leukocyte count was converted to parasite per micro litre of blood using this mathematical formula;

$$
\begin{aligned}
& \frac{\text { Number of parasites }}{\text { Number of leukocytes }} \text { x Total WBC count } \\
& =\text { Parasite per micro litre of blood. }
\end{aligned}
$$

\subsubsection{Principle of the Staining}

Staining usually take place at a neutral $\mathrm{pH}$. $\mathrm{pH}$ of blood is 7.4, when buffered at $\mathrm{pH} 6.8$, it brings the $\mathrm{pH}$ to neutral $\mathrm{pH}$ i.e. $\mathrm{pH}$ 7.0. Unlike charges of stain and blood will attract, the basic part of stain methylene blue stained the acidic part of the cell i.e. the nucleus while the acidic part of stain eosin stained the basic part of the stain i.e. cytoplasm.

\subsubsection{Procedure for Staining Thick Blood Film}

The procedure was described by Monica Cheesbrough, 2005 [27]. 3\% of stock Giemsa stain was diluted in 
buffered water immediately before use. Thick blood film was made on clean grease free glass slide, allowed to airdry and stained with prepared Giemsa stain for 30mintues. Stained slide was rinsed in clean water and allow airdrying before examined under microscope using X100 objective lens. Chromatin of malaria parasite stained dark red and cytoplasm stained blue with Giemsa's stain. The diagnosis of malaria was made with certainty on identification of malaria parasite together with other symptoms associated with malaria infection. The signs and symptoms of malaria infection in humans are caused by the asexual blood stage of the parasite which includes: fever, headache, joint pains, abdominal upset, nausea, vomiting, diarrhoea, and digestive disorders.

The presence of malaria parasite, identification of the species of human parasites and relative malaria parasite count in each blood sample was determined from Giemsa stained thick films and Leishman stained thin blood film. Malaria Parasitaemia was confirmed by microscopic examination using X100 objective lens (oil immersion lens). Malaria Parasitaemia was graded as $+=1-10$ parasites per 100 thick film field, $++=11-100$ parasites per 100 thick film field, $+++=1-10$ parasites per single thick film field, $++++=$ more than 10 parasites per single thick film field after staining for $30 \mathrm{~min}$. Identification of the species of human parasites in the blood films was carried out according to WHO method. A slide was scored as negative when 100 high power fields had been examined for about 30 minutes without seeing any parasites. The amount of relative parasite count in positive smears was done using a simple code from one to four crosses $(+-++++)$ [28].

\subsubsection{Procedure for Staining Thin Blood Film}

Thin blood film was made on clean grease free glass slide and stained using Leishman staining technique; the procedure was described by Monica Cheesbrough, 2005 [27]. Thin blood film was made from well mixed EDTA anticoagulated blood; the film was allowed to air dry and flooded with Leishman stain for 3minutes. The slide was diluted with buffered distilled water and allowed to stain for 10minutes. Slide was rinsed with water; back of the slide was cleaned with damped cotton wool in methylated spirit. The slide was allowed to air dry and examined under microscope using X100 objective lens.

\subsection{Malaria Parasite Count}

The determination of the number of circulating parasites is exceedingly important for clinical purposes to monitor the evolution of the disease and the efficacy of therapy. Quantitative parasitaemia count (Parasite density) was determined by counting the number of asexual parasites (trophozoites, schizonts) present in as many microscopic fields (100x) necessary to count 200 leukocytes in each thick blood film and multiplies by the total white blood cells count of each blood sample. Parasitaemia was graded as low (parasite $<1000 \mu \mathrm{L}^{-1}$ ), moderate $\left(>1000-9,999 \mu \mathrm{L}^{-1}\right.$ ) and high $\left(>10,000 \mu \mathrm{L}^{-1}\right)$ [29].

parasites / ul of blood

$$
\begin{aligned}
= & \frac{\text { Number of observed asexual parasites }}{200(\text { Number of leucocytes counted) }} \\
& \times \text { total WBC count / ul }
\end{aligned}
$$

\subsection{Haematological Parameters Analysised Using Haematology Analyser (Sysmex Automated Haematology Analyser Model KX-21N, Maunfactured By Sysmex Co- Operation Kobe, Japan)}

\subsubsection{Principle}

The aspirated blood sample is measured to a predetermined volume diluted at the specified ratio and then fed into each transducer chamber, which has a minute hole aperture and also contains electrodes through which direct current flows. Blood cells suspended in the diluents sample, pass through the aperture, causing direct current resistance to change between the electrodes, blood cell size is detected by electric pulses. Blood cell count is calculated by counting the pulses and the histogram determined by the pulse sizes.

\subsubsection{Procedure}

Sysmex machine was inspected (for instrument, reagents, waste bin and printer paper) before switch on the machine from power source, machine was calibrated before used and control sample was run along each batches of sample analysis. Well mixed EDTA blood sample was used for the analysis of complete blood count, blood sample was aspirated through the sample probe one after another by pressing start switch, sample was analyzed, rinsed and display the result on the LCD screen of the machine also printed the results out. After the analysis, machine was shut down by aspirating cell clean which washed and rinsed the machine before finally shutdown and switch off from the power source.

\subsubsection{Statistical Analysis}

Results obtained were analyzed using student t-test to compare the means. Analysis was performed using computer database software from the statistical package for social sciences (version 16.0 SPSS). A P-value of < 0.05 was considered statistically significant in all clinical comparisons at $95 \%$ confidence interval.

\section{Results}

Most of the participants were from rural residence and all of them were infected with Plasmodium falciparum species; patients without malaria parasite in their blood were disqualified from the study. Out of the 202 malaria infected patients 129 (63.9\%) were males and 73 (36.1\%) were females; in control subjects 58 (56.9\%) were males and $44(43.1 \%)$ were females. Mean \pm SD of MPC in male was significantly $(\mathrm{P}<0.05)$ higher compared to female in pre and post anti- malaria drug treatment. Mean \pm SD of MPC in both sex for pre anti-malaria drug treatment sex was significantly $(\mathrm{P} \leq 0.05)$ higher compared to post antimalaria drug treatment. Since control subject were at infected with malaria, hence MPC was null. Mean \pm SD of Platelet in male was higher compared to female in pre, post anti-malaria drug and control subjects; the difference was not significant $(\mathrm{P}>0.05)$ except in control subject. Mean \pm SD of Platelet in both sexes for pre anti malaria drug treatment was lower compared to post and control. 
Mean \pm SD of PDW, relative monocyte and absolute monocyte in male was lower compared to female in pre, post anti malaria drug treatment and control subject, the difference was not significant $(\mathrm{P}>0.05)$ except in control subject. Mean \pm SD of PDW, relative monocyte, absolute monocyte in both sexes for control was lower compared to pre and post anti malaria drug treatment. Mean \pm SD of MPV, WBC and absolute neutrophil in male was higher compared to female in pre, post anti malaria drug treatment and control subjects. The difference was significant $(\mathrm{P}<0.05)$ except in control subjects. Mean $\pm \mathrm{SD}$ of MPV, WBC and absolute neutrophil in both sexes for pre anti malaria drug treatment was higher compared to post anti malaria drug treatment and control subjects. Mean \pm SD of relative neutrophil in male was higher compared to female in pre, post anti malaria drug treatment and control subjects. The difference was not statistically significant $(\mathrm{P}>0.05)$. Mean \pm SD of relative neutropil in both sexes for pre anti malaria drug treatment was observed higher compared to post anti malaria drug treatment and control subjects. Mean \pm SD of relative lymphocyte, eosinophil and absolute lymphocyte in male was lower compared to female in pre, post anti malaria drug treatment and control. The difference was significant $(\mathrm{P}<0.05)$ in eosinophil for pre, post anti malaria drug treatment and control subjects; also absolute lymphocyte was significant $(\mathrm{P}<0.05)$ for pre anti malaria drug treatment. Mean \pm SD of relative lymphocyte in both sexes for pre anti malaria drug treatment was observed lower compared to post anti malaria drug treatment and control subjects. However mean \pm SD of relative eosinophil and absolute lymphocyte in both sexes for control subjects was lower compared to pre, post anti malaria drug treatment as shown in table.

TABLE: MEAN \pm SD OF GENDER DIFFERENCES OF BLOOD CELL PARAMETERS ON PRE TREATMENT, POST-ANTIMALARIA DRUG TREATMENT IN MALARIA INFECTED SUBJECTS AND CONTROL

\begin{tabular}{|c|c|c|c|c|c|c|c|c|c|}
\hline \multirow{2}{*}{$\begin{array}{l}\text { GROUPS } \\
\text { Parameters }\end{array}$} & \multicolumn{3}{|c|}{ Pre Treatment } & \multicolumn{3}{|c|}{ Post Treatment } & \multicolumn{3}{|l|}{ Control } \\
\hline & $\begin{array}{l}\text { Male } \\
(\mathrm{N}=129)\end{array}$ & $\begin{array}{l}\text { Female } \\
(\mathrm{N}=73)\end{array}$ & $\begin{array}{l}\mathrm{P} \\
\text { value }\end{array}$ & $\begin{array}{l}\text { Male } \\
(\mathrm{N}=129)\end{array}$ & $\begin{array}{l}\text { Female } \\
(\mathrm{N}=73)\end{array}$ & $\begin{array}{l}\text { p. } \\
\text { value }\end{array}$ & $\begin{array}{l}\text { Male } \\
(\mathrm{N}=58)\end{array}$ & $\begin{array}{l}\text { Female } \\
(\mathrm{N}=44)\end{array}$ & $\begin{array}{l}\mathrm{p} . \\
\text { value }\end{array}$ \\
\hline $\begin{array}{l}\text { MPC } \\
\mu / 1\end{array}$ & $\begin{array}{l}2643.00 \pm \\
474.85\end{array}$ & $\begin{array}{l}2602.20 \pm \\
281.73\end{array}$ & $0.00 *$ & $\begin{array}{l}2373.40 \pm \\
625.99\end{array}$ & $\begin{array}{l}2184.50 \pm \\
300.35\end{array}$ & $0.00 *$ & - & - & - \\
\hline $\begin{array}{l}\text { PLATELET } \\
\mathrm{X} 10^{9 / \mathrm{L}}\end{array}$ & $\begin{array}{l}175.53 \pm \\
52.12\end{array}$ & $\begin{array}{l}156.42 \pm \\
43.89\end{array}$ & 0.09 & $\begin{array}{l}187.74 \pm \\
59.80\end{array}$ & $\begin{array}{l}165.70 \pm \\
50.30\end{array}$ & 0.17 & $\begin{array}{l}292.71 \pm \\
55.25\end{array}$ & $\begin{array}{l}276.34 \pm \\
34.15\end{array}$ & $0.00 *$ \\
\hline $\begin{array}{l}\text { PDW } \\
\mathrm{Fl}\end{array}$ & $\begin{array}{l}13.07 \pm \\
2.33\end{array}$ & $\begin{array}{l}14.54 \pm \\
2.36\end{array}$ & 0.86 & $\begin{array}{l}13.24 \pm \\
2.34\end{array}$ & $\begin{array}{l}14.60 \pm \\
2.46\end{array}$ & 0.66 & $\begin{array}{l}11.75 \pm \\
1.91\end{array}$ & $\begin{array}{l}12.35 \pm \\
1.46\end{array}$ & $0.02 *$ \\
\hline $\begin{array}{l}\text { MPV } \\
\mathrm{Pl}\end{array}$ & $\begin{array}{l}9.85 \pm \\
0.71\end{array}$ & $\begin{array}{l}9.63 \pm \\
0.92\end{array}$ & $0.04 *$ & $\begin{array}{l}9.64 \pm \\
0.53\end{array}$ & $\begin{array}{l}9.55 \pm \\
0.83\end{array}$ & $0.00^{*}$ & $\begin{array}{l}9.52 \pm \\
0.25\end{array}$ & $\begin{array}{l}9.51 \pm \\
0.25\end{array}$ & 0.91 \\
\hline $\begin{array}{l}\text { WBC } \\
\mathrm{X} 10^{9 / \mathrm{L}}\end{array}$ & $\begin{array}{l}6.82 \pm \\
1.81\end{array}$ & $\begin{array}{l}6.45 \pm \\
1.37\end{array}$ & $0.00 *$ & $\begin{array}{l}6.08 \pm \\
2.14\end{array}$ & $\begin{array}{l}5.44 \pm \\
1.52\end{array}$ & $0.00 *$ & $\begin{array}{l}4.49 \pm \\
0.30\end{array}$ & $\begin{array}{l}4.33 \pm \\
0.35\end{array}$ & 0.24 \\
\hline NEUTROPHIL \% & $\begin{array}{l}59.51 \pm \\
9.73\end{array}$ & $\begin{array}{l}52.93 \pm \\
9.07\end{array}$ & 0.41 & $\begin{array}{l}55.05 \pm \\
8.18\end{array}$ & $\begin{array}{l}49.11 \pm \\
7.92\end{array}$ & 0.72 & $\begin{array}{l}58.36 \pm \\
4.78\end{array}$ & $\begin{array}{l}55.86 \pm \\
4.13\end{array}$ & 0.38 \\
\hline $\begin{array}{l}\text { LYMPHOCYTE } \\
\%\end{array}$ & $\begin{array}{l}36.28 \pm \\
9.29\end{array}$ & $\begin{array}{l}41.78 \pm \\
8.39\end{array}$ & 0.24 & $\begin{array}{l}42.94 \pm \\
7.85\end{array}$ & $\begin{array}{l}48.09 \pm \\
7.14\end{array}$ & 0.40 & $\begin{array}{l}40.79 \pm \\
4.67\end{array}$ & $\begin{array}{l}42.56 \pm \\
3.94\end{array}$ & 0.37 \\
\hline $\begin{array}{l}\text { MONOCYTE } \\
\%\end{array}$ & $\begin{array}{l}3.48 \pm \\
2.34\end{array}$ & $\begin{array}{l}4.00 \pm \\
1.84\end{array}$ & 0.84 & $\begin{array}{l}1.64 \pm \\
1.50\end{array}$ & $\begin{array}{l}2.11 \pm \\
1.50\end{array}$ & 0.85 & $\begin{array}{l}0.62 \pm \\
0.85\end{array}$ & $\begin{array}{l}1.34 \pm \\
1.14\end{array}$ & $0.01^{*}$ \\
\hline $\begin{array}{l}\text { EOSINOPHIL } \\
\%\end{array}$ & $\begin{array}{l}0.76 \pm \\
1.02\end{array}$ & $\begin{array}{l}1.03 \pm \\
1.76\end{array}$ & $0.01 *$ & $\begin{array}{l}0.38 \pm \\
0.66\end{array}$ & $\begin{array}{l}0.68 \pm \\
1.17\end{array}$ & $0.00 *$ & $\begin{array}{l}0.19 \pm \\
0.48\end{array}$ & $\begin{array}{l}0.48 \pm \\
0.85\end{array}$ & $0.00 *$ \\
\hline $\begin{array}{l}\text { NEUTROPHIL } \\
\mathrm{X} 10^{9 / \mathrm{L}}\end{array}$ & $\begin{array}{l}4.15 \pm \\
1.51\end{array}$ & $\begin{array}{l}3.43 \pm \\
0.94\end{array}$ & $0.00 *$ & $\begin{array}{l}3.40 \pm \\
1.44\end{array}$ & $\begin{array}{l}2.69 \pm \\
0.88\end{array}$ & $0.00 *$ & $\begin{array}{l}2.63 \pm \\
0.30\end{array}$ & $\begin{array}{l}2.43 \pm \\
0.24\end{array}$ & 0.41 \\
\hline $\begin{array}{l}\text { LYMPHOCYTE } \\
\mathrm{X} 10^{9 / \mathrm{L}}\end{array}$ & $\begin{array}{l}2.39 \pm \\
0.65\end{array}$ & $\begin{array}{l}2.69 \pm \\
0.76\end{array}$ & $0.02 *$ & $\begin{array}{l}2.55 \pm \\
0.87\end{array}$ & $\begin{array}{l}2.62 \pm \\
0.09\end{array}$ & 0.55 & $\begin{array}{l}1.83 \pm \\
0.22\end{array}$ & $\begin{array}{l}1.85 \pm \\
0.24\end{array}$ & 0.62 \\
\hline MONOCYTE X109/L & $\begin{array}{l}0.24 \pm \\
0.20\end{array}$ & $\begin{array}{l}0.25 \pm \\
0.12\end{array}$ & 0.32 & $\begin{array}{l}0.11 \pm \\
0.13\end{array}$ & $\begin{array}{l}0.12 \pm \\
0.09\end{array}$ & 0.40 & 0.03 & $\begin{array}{l}0.06 \pm \\
0.05\end{array}$ & $0.02 *$ \\
\hline
\end{tabular}

$\mathrm{P}<0.05$ Significance, $\mathrm{P}>0.05$ no Significant

\section{Discussion}

Prevalence of $P$. Falciparum specie in this present study was supported by the previous study stated that $P$. falciparum is the predominant specie responsible for malaria infection in Nigeria. Plasmodium falciparum is much more prevalent in sub-Saharan Africa than in many other regions of the world. In most African countries, over $75 \%$ of cases were due to $P$. falciparum. This prevalence of Plasmodium falciparum malaria infection was reportedly higher in male than in female in this present study similar to Akanbi et al., 2010 [30] who concluded that the cause could be due to the fact that males expose their bodies more than females when the weather is hot and thus increases their chances of being bitten by the mosquito. Females, on the other hand, are usually not naked and tend to stay indoors, helping out with household chores. This reduces their contact with the mosquito vector. The observed significantly lower malaria infection prevalence among females compared to males in this study is consistent with finding from other studies; although the cause of these sex differences merits further 
investigation; including the possibility that males produce more attractive chemicals for mosquitoes, the production of estrogens by females have been shown to augment antiplasmodial immune response [31] whereas, testosterone suppresses anti-plasmodial immune responses [32]. Also, studies have shown that females have better immunity to parasitic diseases and this was attributed to genetic and hormonal factors [33]. Contrary to this present study, Azfar et al., 2009 [34] reported a slight female preponderance (56\%) as compared to males (44\%). This is also in contrast to some of the other studies [35] where male to female ratio of up to 2.9:1 was reported. This opposite preponderance may be due to the difference in the geographical distribution. Leukocytes play a vital role in the defence against malaria infection. Leukocyte changes in malaria are variable and depend on many factors such as acuteness of infection, parasitemia, disease severity, state of the host immunity to malaria and concurrent infection [36]. Severity of malaria infection caused by $P$. falciparum observed in this present study is more in male compared to female this might be as a result of different exposure to malaria vector, this was supported by Akanbi et al., 2010 [30] also studies have shown that females have better immunity to parasitic diseases [33]. Overall, the changes seen in blood cell lines in malaria parasitemic patients are usually attributed either to an increase or a decrease in the differential white blood cell lines. The transient malaria blood cell lines are usually attributed to the tissue redistribution of blood cell lines [37] from the free flowing pool to the marginal pool at the endothelial lining of the blood vessels [38]; because of rate of blood cell lines destruction in malaria is much higher in patients with $P$. falciparum infection. Hence, monocytosis has been one of the most consistent observations reported from prior studies done on the blood cell lines changes that characterize malaria [39,40,41]. These findings are in agreement with this present study, mild monocytosis was observed in parasitemic patients compared to the non- parasitemic patients. Significant morphological and numerical changes in all the blood cell lines in malaria infection, before and after anti-malaria drug treatment in this study shows, the effect of antimalaria drug with improvement observed in post antimalaria drug treatment. In this study, although blood cell parameters stayed within the normal range for sex, it was lower significantly in $p$. falciparum parasitemic patients compared to non parasitemic control subjects as observed in this present study.

\section{Conclusion}

Plasmodium falciparum is the most prevalent malaria specie in the study area. Severity and prevalence of malaria infection is more in male compared to female this might be as a result of different exposure to malaria vector and immunity to parasitic infection among the gender.

\section{References}

[1] UNICEF. Rolling back malaria goals. A United Nation Children's Fund document. (2000); 16pp.

[2] WHO/UNICEF. Rapport Surle Palidisme en Afrique; (2003); p 36-59.
[3] Deschamps-Latascha B, Lunel-Fabiani F, Kara-Binis A. Generation of reactive oxygen species in whole blood from patients with acute falciparum malaria. Parasit Immunol; (1987) 9:275-279.

[4] Greve B, Lehman LG, Lell B. High oxygen radical production is associated With fast parasite clearance in children with Plasmodium falciparum malaria. J Infect Dis; (1999) 179: 15841586.

[5] Kremsner, P.G., B. Greve, B. Lell, D. Luckner and D. Schmid. Malarial anemia in African children associated with high oxygenradical production. Lancet, (2000); 355: 40-41.

[6] Alaribe AAA, Ejekie GC, Ezedinachi ENU. The ecology of Bain BJ (1996). Ethnic and sex differences in the total and differential white cell count and platelet count. J Clin Pathol. (2006); 49:664666.

[7] FMOH. Federal Republic of Nigeria Guidelines for Malaria Control. 1990; Pp 24.

[8] Rattan Lal lchhpujan and Rajesh Bhatia. Medical parasitology second edition. Published by Jitendar P.vij Jaypee Brothers, medical Publishers (P) LTD. (1998); chapter 17, pg 113-135.

[9] White NJ. "Assessment of the pharmacodynamic properties of antimalarial drugs in vivo". Antimicrob. Agents Chemother. (1997)41 (7): 1413-1422.

[10] Dondorp A, Nosten F, Stepniewska K. Artesunate versus quinine for treatment of severe falciparum malaria: a randomised trial. Lancet; (2005); 366: 717-725.

[11] Price R. "Adverse effects in patients with acute falciparum malaria treated with artemisinin derivatives". American Journal of Tropical Medicine and Hygiene (1999);60 (4): 547-555.

[12] Krishna. S. "Artemisinins: mechanisms of action and potential for resistance". Drug Resistance Updates (2004); 7: 233-244.

[13] Rahman S. Gender aspects and women's participation in the control and management of malaria in central Sudan. Social Science and Medicine, (1995); 42(10).

[14] Reuben R. Women and Malaria - Special Risks and Appropriate Control Strategy. Social Science and Medicine, (1993); 37(4):473480.

[15] Vlassoff C, Manderson L. Incorporating gender in the anthropology of infectious disease. Tropical Medicine and International Health, (1998); 3(12):1011-1019.

[16] Tin-Oo P. Gender, mosquitoes and malaria: implication for Community development programmes in Lauptta, Myanmar. Southeast Asian Journal of Tropical Medicine and Public Health, (2001); 32(3): 588-594.

[17] Lathia TB, Joshi R. Can hematological parameters discriminate malaria from non malarious acute febrile illness in the tropics? Indian J. Med. Sci. (2004); 58:239-244.

[18] Aduragbenro D. Adedapoa, Catherine O. Faladeab, Rachel T. Kotilac \& George O. Ademowoab. Age as a risk factor for thrombocytopenia and anaemia in children treated for acute uncomplicated falciparum malaria; J Vector Borne Dis (2007); 44, 266-271.

[19] Saleem Ahmed Khan, Waqar Ali. Platelet count in malaria. Pak $J$ Pathol (2008); 86; 19 (3): 86-88.

[20] Facer CA. Hematological aspects of malaria. Infection and Hematology. Oxford: Butterworth Heinmann Ltd., (1994): 259294.

[21] Jandl JH. Hemolytic anemias caused by infection of red cells. In: Blood. $2^{\text {nd }}$ edition. New York: Little Brown and Company (1996): 473-501.

[22] Abdalla SH. Peripheral blood and bone marrow leucocytes in Gambian children With malaria: numerical changes and evaluation of phagocytosis. Ann Trop Paediatr; (1998); 8: 250-258.

[23] Amodu OK, Adeyemo AA, Olumese PE, Gbadegesin RA. Intraleucocytic malaria pigment and clinical severity of malaria in children. Trans R Soc Trop Med Hyg; (1998); 92:54-56.

[24] Biemba G, Gordeuk VR, Thuma P, Weiss G. Markers of inflammation in children with severe malarial anaemia. Trop. Med. Int. Health, (2000); 5: 256-262

[25] McKenzie FE, Prudhomme WA, Magill AJ, Forney JR, Permpanich B, Lucas C, Gasser Jr RA and Wongsrichanalai C. White blood cell counts and malaria. (2005); J. Infect. Dis., 192: 323-330.

[26] Molyneux, M. E., Hien, T. T. and White, N. Clinical Features and Prognostic Indicators in Paediatic Cerebral Malaria: A Study of 131 Comatose Malawian Children. Q. J. Medicine (1989); 78:441.

[27] Monica Cheesbrough. Discrete Laboratory Practice in Tropical Countries Part 1, Cambridge Second Editions. Published by Press 
Syndicate of the University of Cambridge, (2005); chp. 5, page 247-258.

[28] Dayachi F, Kabongo L, Ngoie K. Decreased mortality from Malaria in children with symptomatic HIV infection. Int. Cont. AIDS (1991); 2: 164.

[29] Warhurst, D.C. and J.E. Williams. Acp Broadsheet no 148. July 1996. Laboratory diagnosis of malaria. J. Clin. Pathol., (1996); 49: 533-538.

[30] Akanbi, O.M., J.A. Badaki, O.Y. Adeniran and O.O. Olotu. Effect of blood group and demographic characteristics on malaria infection, oxidative stress and haemoglobin levels in South Western Nigeria. Afr. J. Microbiol. Res., (2010); 4: 877-880.

[31] Cernetich A, Garver L S, Jedlicka. Involvement of gonadial steroids and gamma interferon in sex differences in responses to blood stage malaria infection. Infect Immum; (2006); 63: 222-230.

[32] Krucken J, Dkhil M A, Braun J V. Testosterone suppresses protective responses of the liver to blood stage malaria. Infect imumm; (2005)73:436-443.

[33] Zuk M, McKean KA. Sex differences in parasite infections: patterns and processes. Inter J Parasitol; (1996); 26: 1009-1023.

[34] Azfar Farogh, A. Qayyum, Aamir HaleemM, and A. Ghaffar. Haematological abnormalities in malaria; Biomedica (2009); Vol.25, 52-55.
[35] Bashwari LA, Mandil AM, Bahnassy AA, AI-Shamsi MA Bukhari HA. Epidemiological profile of malaria in a University hospital in the eastern region of Saudi Arabia. Saudi Med J; (2001); 22 (2): 133-8.

[36] Abdalla S.H and Pasvol. G. Malaria: A Hematolgical Perspective, Impeerial College Press, London, Uk. (2004).

[37] Hviid. L, Kemp. K, Kern.P. What is the cause of lymphopenia in malaria infection and immunity; (2000); vol68, N0 10, pp 60876089.

[38] Dale D.C and Wolff S.M. Studies of the neutropenia of acute malaria. Blood; (1973); vol41, N0 2, pp 197-206.

[39] Maina R.N, Walsh. D, Gaddy. C. Impact of Plasmodium falciparum infection on haematological parameters in children living in Western Kenya, Malaria Journal, (2010); vol. 9, no. 3.

[40] Akhtar. S, Gumashta. R, Mahore. S and Maimoon. S. A hematolgical changes in malaria a comparative study, journal of pharmacy and Biological Sciences, (2012); vol 2, no 4, pp. 15-19.

[41] Kueh Y.K and Yeo K.L. Haematological alterations in acute malaria, Scandinavian Journal of Haematology, (1982); vol.29, no. 2, pp 147-152. 